\title{
Impurities Effect on the Charge Mobility of Yttria-Stabilized Zirconia
}

\author{
Menna M. Abo-Zeid ${ }^{1}$, Mohamed S. El-Deab ${ }^{1}$, A. AbdelKareem ${ }^{2}$, \\ Omayma A.M. El-Kady ${ }^{3}$ and A. M. Daher, ${ }^{2, *}$ \\ ${ }^{1}$ Department of Chemistry, Faculty of Science, Cairo University, Cairo, Egypt. \\ ${ }^{2}$ Nuclear Materials Authority, Cairo, Egypt. \\ ${ }^{3}$ Powder Metallurgy Division, Manufacturing Technology Department, Central Metallurgical R\&D \\ Institute (CMRDI), P.O. BOX 87 Helwan, 11421 Cairo, Egypt. \\ *E-mail: doctor_daher@yahoo.com
}

doi: $10.20964 / 110403137$

Received: 26 December 2015 / Accepted: 19 January 2016 / Published: 1 March 2016

The present study is concerned with the preparation of yttria-stabilized zirconia (YSZ) having high charge mobility. Herein, we studied the doping of zirconia with different concentrations of $\mathrm{Y}_{2} \mathrm{O}_{3}$. The samples were prepared by a solid state reaction at 800,1000 , and $1200^{\circ} \mathrm{C}$ for 2 hours. The morphology of the pellets was characterized by scanning electron microscope (SEM). Crystallinity and phase change were studied by X-ray diffraction (XRD). The electrical conductivity of the sintered pellets was measured and demonstrated that the conductivity increase as yttria content increase. We have also found that the conductivity decreased with increasing the level of the impurities in the natural ore.

Keywords: Yttria-stabilized Zirconia; clusters; composite materials; solid state reactions; crystal structures.

\section{FULL TEXT}

(C) 2016 The Authors. Published by ESG (www.electrochemsci.org). This article is an open access article distributed under the terms and conditions of the Creative Commons Attribution license (http://creativecommons.org/licenses/by/4.0/). 